Revista Aspas

ppgac - USP

Artigo

\title{
BRICOLAGEM METODOLÓGICA NA COMPREENSÃO DE PERFORMANCES INTERATIVAS NO ESPAÇO PÚBLICO
}

METHODOLOGICAL BRICOLAGE IN THE UNDERSTANDING OF INTERACTIVE PERFORMANCES IN THE PUBLIC SPACE

\author{
BRICOLAJE METODOLÓGICO EN LA COMPRENSIÓN DE \\ PERFORMANCES INTERACTIVAS EN EL ESPACIO PÚBLICO
}

\section{Vanessa Sonia Santos}

Vanessa Sonia Santos

Doutora em Comunicação pela Universitat

Pompeu Fabra, com a tese Designing mobile narratives: discursive strategies and participation modes in locative media art, sob orientação do

Dr. Roc Parés Burguès 


\section{Resumo}

Este artigo discute novas perspectivas na condução de estudos acadêmicos que possam gerar um pluralismo metodológico a partir da aproximação entre reflexão teórica e elaboração prática. Apresenta um projeto de pesquisa que incluiu a concepção da performance Chronica Mobilis para exemplificar como o processo de criação artística pode servir como meio principal de entendimento da experiência, tanto do pesquisador, convertido em realizador, quanto das pessoas em relação à obra concebida. A bricolagem metodológica feita pelo estudo mencionado, em uma combinação entre fazer artístico e métodos científicos tradicionais, sinaliza para um conhecimento que também pode ser adquirido com o processo prático. Este artigo argumenta em favor da validade e da legitimação desse método, apontando para a criação de um saber no sentido experiencial.

Palavras-chave: Espaço público, Performance, Metodologia, Participação, Prática artística.

\section{Abstract}

This article discusses new perspectives in the conduction of academic studies that can generate a methodological pluralism through the approximation of theoretical reflection and practical elaboration. It presents a research project that included the design of the performance Chronica Mobilis to exemplify how the artistic creation process can serve as the main mechanism to the understanding of the experience of both, the researcher-artist and the people in relation to the work conceived. The methodological bricolage made by the aforementioned study, in a combination between artistic and traditional scientific methods, points to a knowledge that can also be acquired through the practical process. This article argues for the validity and legitimation of this method to the creation of knowledge in the experiential sense.

Keywords: Urban space, Performance, Methodology, Participation, Artistic practice. 


\section{Resumen}

Este artículo discute nuevas perspectivas en la conducción de estudios académicos, que puedan generar un pluralismo metodológico desde la aproximación entre reflexión teórica y elaboración práctica. Presenta un proyecto de investigación que incluyó la concepción de la performance Chronica Mobilis para ejemplificar cómo el proceso de creación artística puede servir como medio principal de entendimiento de la experiencia, tanto del investigador, convertido en realizador, como de las personas en relación a la obra concebida. El bricolaje metodológico realizado por el estudio mencionado, en una combinación entre hacer artístico y métodos científicos tradicionales, señala para un conocimiento que también puede venir del proceso práctico. Este artículo argumenta en favor de la validez y legitimidad de este método para la creación de un saber en el sentido experiencial.

Palabras clave: Espacio público, Performance, Metodología, Participación, Práctica artística.

\section{Introdução}

Novas perspectivas na condução de estudos acadêmicos podem desempenhar papel formativo na definição de parâmetros para a investigação no domínio das Artes e das Ciências Humanas. Algumas abordagens dedicadas a gerar um certo pluralismo metodológico têm procurado evitar a simples aceitação de métodos científicos convencionais para explorar modos alternativos de saber. Esse é o caso de pesquisadores (CANDY, 2011; GALLOWAY, 2008; KINCHELOE, 2005; ROLLING, 2013) que apostam na possibilidade de mudar crenças canônicas sobre a forma como uma investigação científica deve ser conduzida, a partir de uma aproximação entre reflexão teórica e elaboração prática. "Art-Based Research", ou pesquisa baseada em Artes, demonstra tal esforço em reconhecer que conhecimento também pode ser obtido quando o processo de criação artística é incluído como mecanismo essencial de investigação (EISNER, 2006; MCNIFF, 2008). Este artigo se propõe a uma reflexão sobre tal bricolagem metodológica, identificando essas contribuições que o 
desenvolvimento prático de uma obra de arte pode exercer na geração de conhecimento sobre determinado fenômeno.

Para explorar o potencial do fazer artístico como parte integral da pesquisa científica, será tomado como estudo de caso o projeto de doutorado ${ }^{1}$ que culminou na criação de Chronica Mobilis ${ }^{2}$, uma performance intermedial e interativa que acontece no espaço público. A pesquisa analisa o impacto e a influência das mídias móvel e locativa³ (LEMOS; JOSGRILBERG, 2009, p. 91-92) na formulação de determinadas experiências artísticas participativas no ambiente das cidades. O referido estudo acadêmico tem como foco a emergência de maneiras particulares para narrar e experimentar histórias em um espaço público expandido com dados digitais. Complementar à reflexão teórica sobre as formas discursivas e os modos de participação propostos nessas práticas, a investigação traça como objetivo: reconhecer as particularidades no desenho e na implementação dessas intervenções artísticas, e avaliar uma possível correlação entre alguns tipos de engajamento e a experiência resultante.

\section{Bricolagem metodológica}

A bricolagem metodológica, como define Kincheloe (2005), significa aceitar que não há metodologias universalmente aplicáveis e corretas, que métodos devem vir em resposta a situações particulares e demandas específicas geradas pelo questionamento de pesquisa. Evitando o emprego único de modos de raciocínio e de verificação que provêm de processos certificados

1. SANTOS, V. S. Designing mobile narratives: discursive strategies and participation modes in locative media art. 2017. 469 f. Tese (Doutorado em comunicação), Departament de Comunicació, Universitat Pompeu Fabra, Barcelona, 2017. Diretores: Dr. Roc Parés Burguès (Departamento de Comunicação, UPF) e Dra. Karla Schuch Brunet (Departamento Multidisciplinar de Cultura e Sociedade, UFBA).

2. Disponível em: <https://goo.gl/tzEW2F>. Acesso em: 23 fev. 2018.

3. O termo "mídia locativa" foi inicialmente cunhado por Marc Tuters e Kazys Varnelis como título para uma oficina em 2002, organizada pela RIXC, centro de mídia e arte eletrônica da Letônia. O termo deriva do nome "locativo", que na língua letã indica localização. Lemos e Josgrilberg (2009) definem mídia locativa como as interfaces tecnológicas baseadas em sistemas de rastreamento digital que possibilitam a interação entre redes físicas, sociais e digitais. As mídias locativas permitem identificar o posicionamento de pessoas e objetos no espaço físico, gerando dados que informam onde estamos, o que estamos fazendo e como podemos interagir com o meio ambiente. Os telefones celulares com receptores de Sistema de Posicionamento Global (GPS), tecnologias 3G e Bluetooth são alguns dos dispositivos habilitados pelas tecnologias locativas. 
por uma análise lógica, bricoleurs procuram reexaminar interpretações aceitas, revelar novas ideias e alterar antigos princípios, sem tentar ajustar questões de pesquisa a um método fixo (KINCHELOE, 2005, p. 234). A bricolagem metodológica representa um desafio ativo de encontrar ou criar ferramentas capazes de conectar disciplinas e conhecimentos.

O projeto de pesquisa que incluiu a criação de Chronica Mobilis demandou a aplicação de múltiplas ferramentas de investigação para a compreensão do objeto delimitado. A definição da metodologia a ser utilizada ocorreu em resposta às perguntas planteadas para o estudo, e não necessariamente aceitando a hegemonia de métodos científicos tradicionais tidos por vezes como os únicos meios legitimados para revelar certas verdades.

Figura 1 - As três etapas da pesquisa, com seus respectivos objetivos e locais de realização

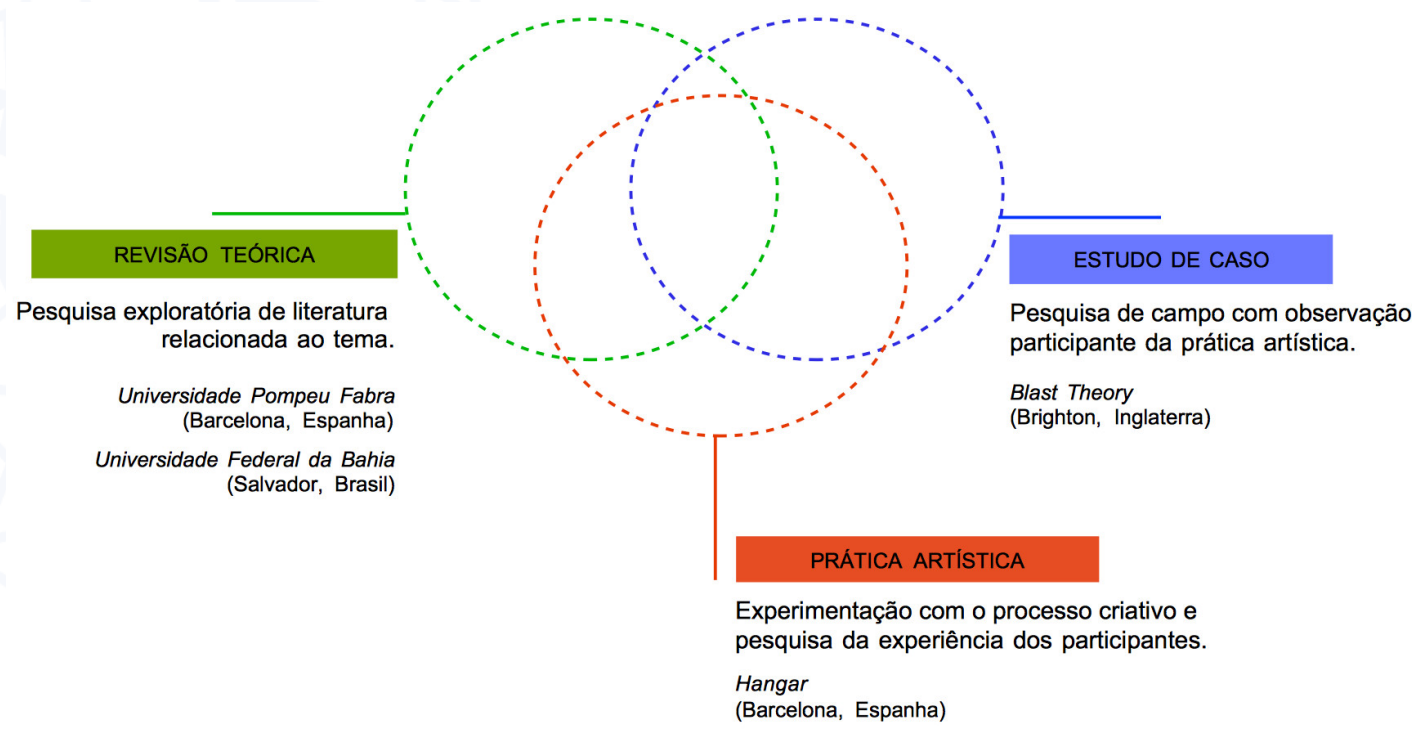

Fonte: Elaborada pela autora, 2017

O resultado é uma investigação científica que aproxima reflexão teórica e elaboração prática e que dilui uma possível distância que separa o pesquisador do realizador. A abordagem conduziu a uma metodologia de caráter interdisciplinar, que cruza os limites de domínios normalmente separados: Arte, Ciência e Tecnologia. O plano de trabalho compreendeu três fases complementares, que incluíram teoria, avaliação e prática; ou mais especificamente: ver, fazer e analisar. 


\section{Pesquisa teórica}

O estudo tem início com uma ampla e exploratória revisão de literatura para identificar as discussões teóricas e analíticas articuladas com o objeto e as questões a serem investigados. Os primeiros artistas a trabalharem com intervenções artísticas geolocalizadas no espaço urbano apontavam para a natureza dos espaços públicos, e em alguns casos adereçavam um olhar crítico para a capacidade de monitoramento da tecnologia empregada em suas obras (TUTERS; VARNELIS, 2006). Mais de dez anos após o surgimento do movimento de Arte Locativa, local e contexto espacial continuam a serem usados na criação de um novo senso de consciência do lugar, das interações sociais e participativas, e de um ativismo sociopolítico. Essas obras tendem a representar o ato de narração integrado à informação histórica, etnográfica e arquitetônica fornecida pela paisagem urbana. São práticas artísticas espacialmente contextualizadas cuja interação é projetada com base no movimento e na localização dos participantes, algo que também serve de inspiração, conteúdo, materialidade e contexto (ACETI, 2016, p. 10). São práticas artísticas socialmente conectadas em rede e participativas que interagem com o local e destacam as possibilidades políticas de tecnologia (SHELLER; IVERSON, 2016, p. 15-18).

Essa etapa do estudo contribuiu para identificação e articulação desses aspectos essenciais e definidores desse tipo de prática artística. Além disso, trouxe referências e definiu parâmetros e categorias que fundamentaram a formulação de um modelo de análise dedicado à compreensão qualitativa de obras nesse domínio. O modelo e suas categorias foram organizados em três níveis: a interação com o conteúdo, a interface com o sistema e a experiência gerada. A motivação na criação desse modelo era expandir o entendimento dessas práticas artísticas e avaliar a maneira como utilizam dispositivos móveis e tecnologias de geolocalização para propor ao público uma experiência corporificada pelas ruas da cidade.

\section{Pesquisa etnográfica}

A etapa subsequente da pesquisa consistiu em mapeamento e reconhecimento das obras existentes, estabelecendo como estudo de caso o 
grupo britânico Blast Theory ${ }^{4}$. Os artistas Matt Adams, Ju Row Farr and Nick Tandavanitj são renomados internacionalmente pelo uso que fazem da tecnologia: experimentam novas formas interativas de performance que acontecem no espaço urbano. $\mathrm{O}$ grupo atuou em inúmeros projetos de pesquisa, por meio de uma longa colaboração estabelecida com o Mixed Reality Lab, da Universidade de Nottingham. Desde os anos 1990, investigam a interatividade e o papel da audiência, gerando um diálogo interdisciplinar entre pesquisa científica e prática artística.

Essa fase da investigação, com um viés etnográfico, incluiu uma visita de campo aos estúdios do Blast Theory, localizado na cidade de Brighton, Inglaterra. A pesquisa de campo representou, primeiramente, uma oportunidade de acesso aos arquivos analógicos e digitais mantidos pelos artistas. No espaço, o grupo possui documentado todo o processo criativo de cada uma de suas obras. Esses arquivos guardam materiais gráficos, como desenhos, fotos e referências visuais, assim como reflexões escritas e avaliações feitas no decorrer do processo artístico de cada obra. É um material de grande relevância, uma vez que Blast Theory desenvolve seus projetos seguindo um método iterativo baseado em playtestes (ZIMMERMAN, 2003, p. 176-177). Como são trabalhos participativos, que utilizam tecnologia e acontecem em um espaço fluido como o das cidades, o grupo precisa fazer constantes ajustes na implementação de suas ideias. Essas reformulações, realizadas de acordo com os resultados encontrados a cada prova, podem envolver tanto aspectos interativos do sistema quanto questões relacionadas ao conteúdo. O acesso a esta documentação arquivada desvela informações relevantes sobre as especificidades do processo de criação e a implementação de performances interativas geolocalizadas no espaço urbano.

A pesquisa de campo representa também uma oportunidade para a observação participante. Participante, sobretudo, porque a visita da pesquisadora foi mais propriamente uma estância de colaboração com duração de três meses, na qual esteve envolvida diretamente nas atividades diárias e práticas artísticas do grupo britânico. Essa aproximação e vivência representou uma oportunidade singular para o acompanhamento, desde o princípio, do

4. Disponível em: <https://goo.gl/QMqvgj>. Acesso em: 23 fev. 2018. 
processo de desenvolvimento de uma nova obra. Serviu também para observar como funciona a preparação para a turnê com os projetos, preparativos que incluem desde adaptações do conteúdo narrativo das obras de acordo com o local a ser apresentado, até testes para verificação e preparação dos equipamentos específicos utilizados em cada obra. Todas essas atividades contempladas durante a visita de campo permitem identificar e avaliar como os artistas pensam as relações entre o conteúdo e os usos social e político da tecnologia; como refletem sobre o espaço urbano e incluem isso como uma demanda ativa no desenvolvimento de uma obra; como discutem e de onde tomam inspirações para as questões estéticas e de conteúdo; como experimentam com a participação do público nesses tipos de trabalhos artísticos.

Entrevistas com os artistas é outro método de coleta de dados utilizado durante a pesquisa de campo, que desvela informações relevantes para o estudo. $O$ roteiro de perguntas, nesse caso, encontra a possibilidade de não se restringir à vasta bibliografia referente aos trabalhos realizados pelo Blast Theory, mas de propor uma reflexão conectada às observações da prática e dos materiais de arquivo. As entrevistas dão voz e permitem reconhecer o ponto de vista e a reflexão individual de cada um dos três artistas sobre sua prática. Realizadas separadamente, enfatizam a importância e o caráter de um grupo que é interdisciplinar. Essas conversas focam essencialmente em quatro projetos: I like Frank (2004), Rider spoke (2007), A machine to see with (2010) e Fixing point (2011). Blast Theory emprega a tecnologia e utiliza o espaço urbano em cada uma dessas obras a partir de uma perspectiva distinta, sendo por isso eleitas como objetos de análise nessa etapa da pesquisa.

A identificação de aspectos do processo criativo desses artistas aliada à análise qualitativa desses quatro projetos gera uma compreensão formal, conceitual e relacional do fenômeno estudado. A análise segue as categorias do modelo consolidado no estágio inicial do estudo, mas o objetivo principal não é de rotular as obras de acordo com conceitos predeterminados ou um sistema fixo. Esse conhecimento não se destina a testar uma hipótese ou a criar reduções teóricas. Sua relevância encontra-se essencialmente na possibilidade de identificar a diversidade de estratégias adotadas para a organização do conteúdo narrativo e para o engajamento do público neste tipo de 
intervenções artísticas. Essa é uma contribuição importante ${ }^{5}$ para a terceira etapa da pesquisa acadêmica ancorada na prática.

\section{Elaboração prática}

A proposta dessa pesquisa científica é uma reflexão sobre o problema investigado que vai além do uso de estudos de caso, entrevistas e outros textos explanatórios. Para atender a esses objetivos, a pesquisadora, convertida em realizadora, é colocada a se envolver em algo mais empírico e prático. O terceiro estágio desse estudo inclui o desenvolvimento de um trabalho artístico cujo processo de criação é estruturado por uma série de questões de pesquisa e objetivos. A condução da prática é destinada a gerar conhecimento sobre: 1) como implementar as tecnologias envolvidas nesse tipo de projeto artístico; e 2) entender como o público responde a alguns modos particulares de engajamento.

A prática exerce um papel significante no campo da pesquisa em arte interativa, ainda que esses tipos de processos criativos dependam de um conhecimento tecnológico e técnico, o que inclui alguns obstáculos consideráveis a serem superados no processo de investigação (CANDY, 2011, p. 38-39). Com relação aos obstáculos tecnológicos, a pesquisadora-realizadora seguiu a rota da colaboração. Hangar - centro para pesquisa e produção de Artes Visuais -, situado na cidade de Barcelona, Espanha, recebeu o projeto em sua linha de investigação em mídias locativas e apoiou as atividades decorrentes dessa prática artística. Um grupo de pesquisadores, tecnólogos e artistas se reuniram ao projeto por meio de chamadas públicas para colaboração. Juntos, um grupo interdisciplinar de 20 pessoas compartilharam a experiência prática de criar a performance interativa Chronica Mobilis destinada a fins de investigação.

5. Chronica Mobilis, a obra desenvolvida no estágio final dessa pesquisa de doutorado, faz referência em especial aos trabalhos do Blast Theory que experimentam as possibilidades de integração entre os espaços físico e virtual. A obra toma como inspiração I like Frank (2004), considerado o primeiro jogo de realidade mista para telefones celulares 3G. 
Figura 2 - Estrutura que guiou o processo prático de desenvolvimento da obra

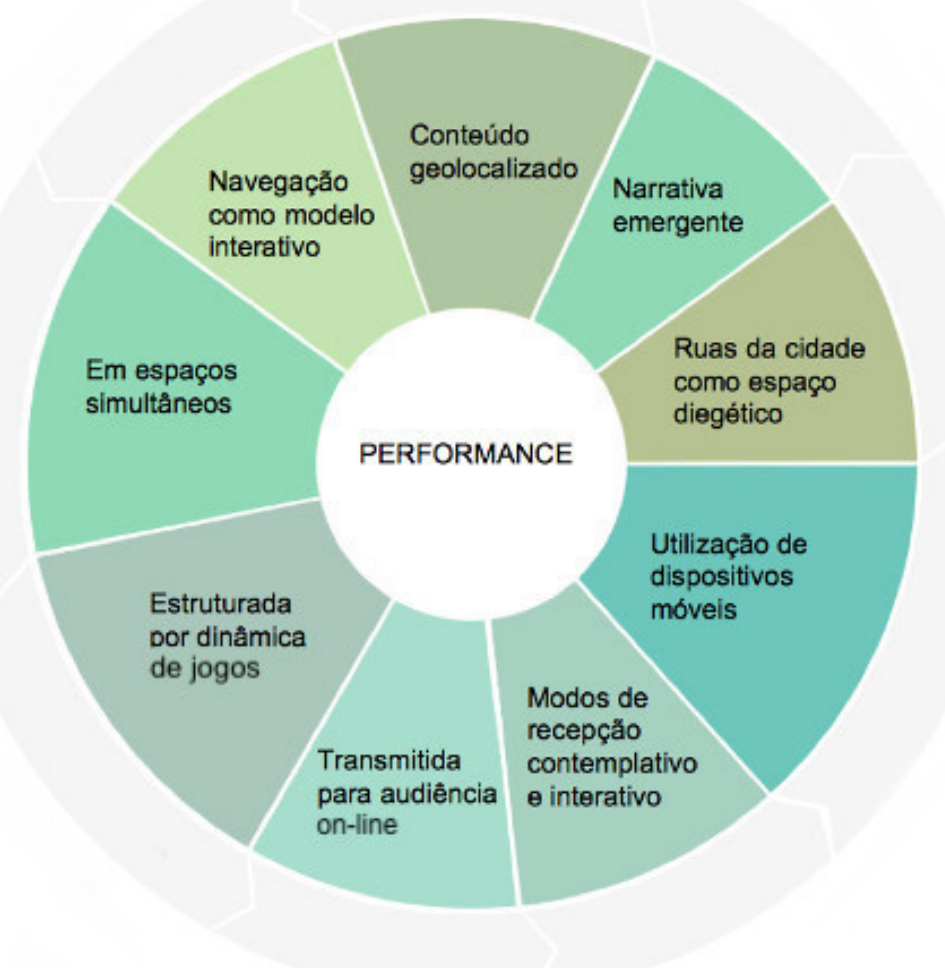

Fonte: Chronica Mobilis, 2014.

A prática artística envolvida no processo de criação de Chronica Mobilis permitiu: 1) reconhecer as potencialidades e restrições dos sistemas comunicativos que dão suporte à performance, 2) experimentar com a possibilidade técnica de implementação de determinadas estratégias narrativas lineares e não lineares, 3) investigar a integração de modos de participação e de recepção contemplativos e interativos. Com o questionamento da pesquisa inserido dentro da própria prática, a obra pronta significou uma oportunidade para a compreensão da experiência dos participantes de acordo com as diferentes formas de engajamento possibilitadas pela performance. Esse aspecto foi avaliado por meio de questionários aplicados logo após a apresentação pública da obra, na qual aqueles que estiveram presentes e participaram dela reportaram sua experiência interativa. Essas descrições foram posteriormente analisadas e agrupados em três níveis: aspectos relativos à interação, ao conteúdo, e à sensação e emoção geradas. Esse conhecimento permitiu não só um entendimento da experiência do público em geral com a obra, mas 
também possibilitou uma comparação entre a experiência relacionada às diferentes categorias de participação.

\section{Chronica Mobilis}

Chronica Mobilis é uma experiência narrativa geolocalizada no espaço público. A performance repensa as opções para a narração integrando diferentes camadas de informação, espaços distintos e categorias de participação. Apresentada simultaneamente dentro de um espaço de exibição e pelas ruas da cidade, permite às pessoas participarem, seja interagindo ou apenas assistindo à apresentação. Os que escolhem interagir o fazem de dois modos: navegando pelas ruas da cidade ou a partir de computadores que se encontram dentro do local onde acontece a apresentação. Em uma posição contemplativa, aqueles que optam por assistir permanecem sentados dentro deste mesmo espaço onde são exibidos os conteúdos.

A performance apresenta uma história de ficção que retrata a vida de um personagem e de um bairro ao longo de 30 anos. A trama tem como conflito central o processo urbano de gentrificação. A narrativa, fragmenta$\mathrm{da}$, apresenta o que seriam as lembranças desse personagem. Funciona como um diário mental e seletivo de memórias, que evidenciam uma pessoa e um espaço urbano em constante mutação. Essas recordações de eventos que aconteceram em tempos narrativos e locais distintos aparecem como fragmentos em cenas de vídeo. Cada uma dessas doze cenas são geolocalizadas como um quebra-cabeça pelo bairro de Poblenou, em Barcelona. $\mathrm{O}$ ato narrativo requer o deslocamento físico daqueles que escolhem participar da performance interagindo. Estes precisam explorar o espaço urbano, seja presencialmente nas ruas ou remotamente usando os computadores, e trabalhar em equipe para encontrar os locais onde que desvelam as partes dessa história. A narrativa se desenvolve de acordo com o progresso deles em encontrar esses lugares. Cada vez que os que estão nas ruas visitam um desses pontos, a cena de vídeo geolocalizada ali é exibida dentro do espaço da performance. Essa cena traz uma memória do personagem, uma recordação de algum evento vivenciado por ele naquele exato lugar. 
Figura 3 - Narrativa com seus fragmentos geolocalizados que participantes precisam encontrar

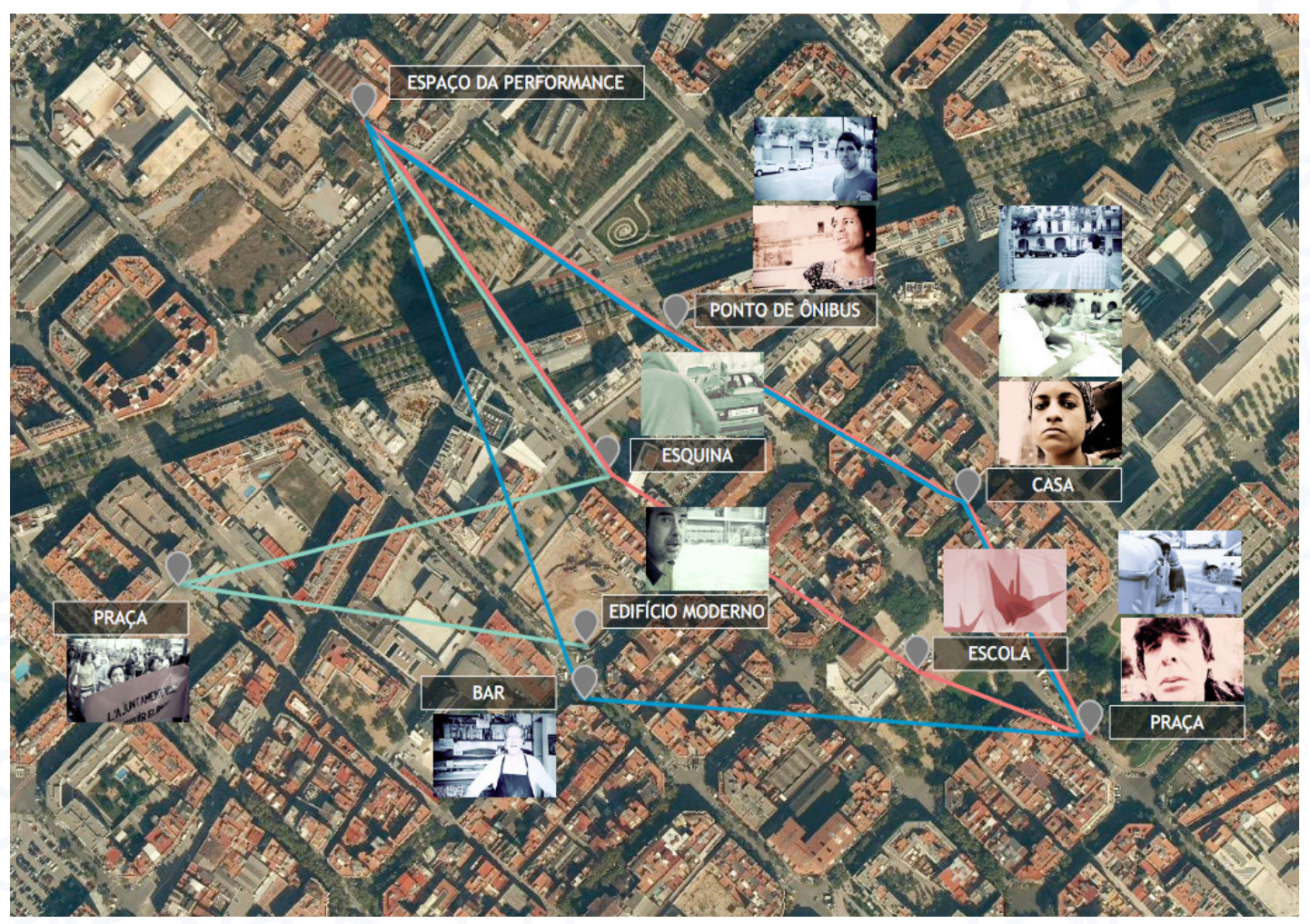

Fonte: Chronica Mobilis, 2014.

O significado de experiência que a performance propõe não reside apenas nas cenas que os jogadores coletam pela cidade, mas sobretudo na participação corporificada e performativa que a obra demanda deles. Os que interagem em Chronica Mobilis agem em um comportamento que vai além de um mero clique para recuperar os fragmentos narrativos. Eles se convertem em contadores de histórias, atuando dentro do universo narrativo da performance. Estratégias lúdicas motivam suas ações dentro do espaço diegético e os envolve em uma experiência exploratória pelas ruas da cidade. Acabam por construir uma história paralela que se fundamenta em seu comportamento. Dão forma a um discurso narrativo emergente que resulta de atos inesperados e não definidos previamente. São agentes e espectadores, vivem e observam a formação do conteúdo narrativo. 
Figura 4 - Camadas de dados geradas pelos participantes e exibidas ao público

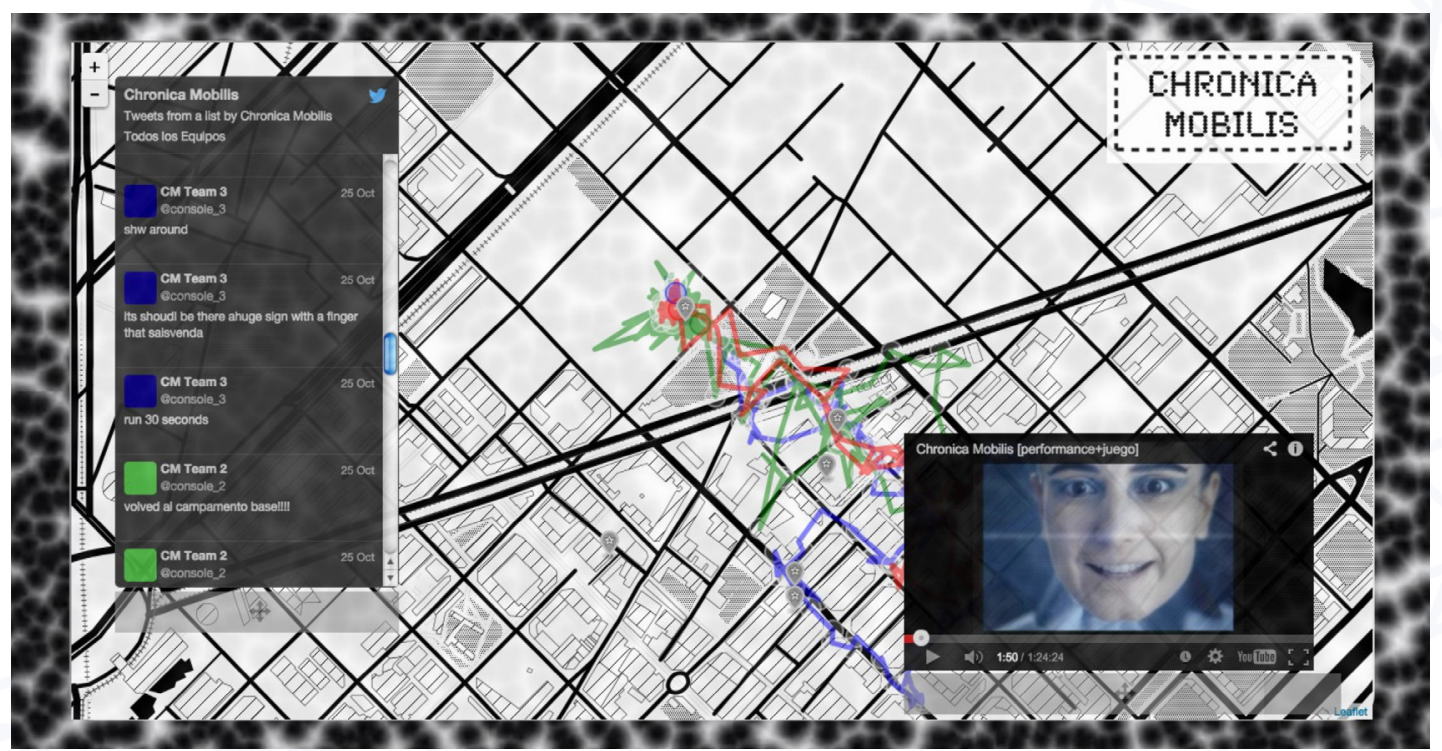

Fonte: Chronica Mobilis, 2014.

Há várias camadas de significado em Chronica Mobilis. Grande parte delas é gerada por aqueles participantes que interagem, sendo combinadas em tempo real por Video Jockeys (VJs), para serem exibidas ao público que se encontra dentro do espaço de exibição. Dados de geolocalização coletados dos telefones celulares geram um mapa psicogeográfico com os deslocamentos em tempo real pelo espaço urbano. Vídeo e áudio são gravados e transmitidos através dos telefones celulares como uma maneira de autorreporte da experiência vivida nas ruas. Mensagens de texto com orientação enviada pelos participantes on-line são também recebidas nos aparelhos móveis. Fragmentos de vídeo com cenas da histórica de ficção aparecem de acordo com o progresso dos jogadores na exploração do espaço urbano. Cada categoria de participantes produz uma dessas camadas em tempo real, enquanto o público contempla a apresentação desses conteúdos de dentro do espaço onde é feita a apresentação.

\section{Processo de desenvolvimento}

O processo de desenvolvimento de Chronica Mobilis seguiu a mesma metodologia iterativa utilizada por Blast Theory. Os resultados obtidos depois de sucessivos testes serviram para refinar progressivamente a estrutura interativa de acordo com os resultados obtidos nos experimentos. Perguntas 
diferentes guiaram cada uma das muitas provas realizadas, entre elas: se a tecnologia poderia suportar todas as funções requeridas pelo modelo de interação criado, se a dimensão lúdica estava desempenhando os objetivos esperados, ou ainda se os participantes poderiam entender como era esperado que atuassem.

Outra etapa importante do processo de desenvolvimento e implementação de Chronica Mobilis incluiu encontrar os lugares na cidade para geolocalizar os fragmentos narrativos. As cenas dessa história ficcional foram imaginadas, criadas e escritas tendo em mente o lugar que o conteúdo seria geolocalizado. Algumas viagens exploratórias pelas ruas do bairro de Poblenou, em Barcelona, serviram para definir esses pontos. As navegações pelas ruas seguiram as premissas e técnicas do Situacionismo, como a deriva com deslocamentos não planejados pelo bairro (DEBORD, 1958). Selecionados os locais, estes serviram como fonte de inspiração para escrita da história, que incorporou uma série de elementos encontrados no espaço físico. Foram também nestes mesmos pontos do bairro onde os participantes teriam de visitar, que cada cena de vídeo foi gravada para forjar uma correspondência entre localidade e conteúdo, entre ficção e não ficção.

\section{Conhecimento gerado pela prática criativa}

"Arts-based research", ou ABR, assim como define McNiff (2008, p. 29), refere-se ao uso sistemático de processos de criação artística como meio principal de entendimento e inspeção da experiência, tanto dos pesquisadores quanto das pessoas envolvidas por eles em seus estudos. $O$ autor enfatiza que a pesquisa baseada na prática é uma mudança metodológica capaz de trazer intuições, resolver ou revisar problemas que são simplesmente inviáveis por meio da linguagem descritiva e linear. Ao relatar o momento de criação do "Art-Based Institute", em 1993, na Universidade de Stanford, Eisner (2006) relembra que seu objetivo inicial era que as artes poderiam ser usadas de uma maneira mais produtiva para ajudar no entendimento mais imaginativo, emocional e expressivo de problemas e práticas que merecem atenção. As artes deveriam estar no centro da pesquisa, ou a pesquisa deveria estar enraizada nas artes, já que estes processos criativos permitem 
acessar formas de experiência que são difíceis de se alcançar por meio de outros modos de representação. A pesquisa baseada em arte, como avalia Greenwood (2016), cresce exatamente dessa busca por métodos que evitem possíveis restrições de formas predominantemente intelectuais e verbais para explorar certas questões. Um estudo com este foco metodológico é capaz de gerar um conjunto de dados que possuem relevância no entendimento de uma série de questões de pesquisa. Em vez de um relatório de evidências empíricas, produz um entendimento conceitual do fenômeno.

A experimentação prática que resultou em Chronica Mobilis levou a pesquisadora a um exame direto dos aspectos relacionados à criação do tipo de obra investigada, assim como a obra em si também permitiu fazer uma avaliação da experiência dos participantes em relação ao trabalho concebido. $O$ conhecimento gerado pela prática esteve conjugado, de forma complementar, a uma cognição mais lógica. As questões a serem pesquisadas foram respondidas por meio de palavras, mas também pelo processo artístico. A pesquisadora criou uma obra e sistematicamente descreveu e refletiu sobre o que foi feito, comparando sua experiência pessoal à experiência de outros, assim como contrapôs seus achados ao que consta na literatura publicada sobre o assunto. Tal protocolo de pesquisa operou em uma desmistificação da separação feita entre pesquisa científica e prática. $O$ resultado é um método de investigação mais experimental, empírico e direto do processo artístico, quando comparado ao conhecimento que se poderia gerar apenas entrevistando outros profissionais ou descrevendo obras e processos.

\section{Aplicação metodológica da prática na arte interativa}

No âmbito da arte interativa, como descrito por Candy (2011), a investigação acontece principalmente em duas áreas inter-relacionadas: a primeira como um modo de investigar a maneira de se implementar algumas tecnologias envolvidas neste tipo de projetos artísticos, e a segunda como uma pesquisa direcionada à compreensão de como o público pode responder a experiências interativas específicas. Conforme mencionado anteriormente, a inclusão da prática na pesquisa acadêmica que criou Chronica Mobilis teve como objetivo investigar tanto o processo de criação e implementação de 
uma performance intermedial quanto a experiência do público em resposta a sua participação nesta obra.

A compreensão da significância e contribuição do conhecimento gerado pela prática no contexto da pesquisa científica, como observa Candy (Ibid.), só é possível com uma referência direta à obra, já que esta serve de base para a exploração de ideias através do fazer. O próprio processo de desenvolvimento oferece oportunidades de reflexão e avaliação, posto que por si mesmo conduz à transformação da ideia e da concepção inicial. As questões a serem investigadas não são todas eleas estabelecidas com antecedência, assim como as formas tradicionais de pesquisa comumente o fazem. Nesse caso, novos questionamentos também surgem durante o processo de elaboração, em uma iteração entre fazer, refletir e gerar questões, que são abordadas, por sua vez, fazendo ainda mais, refletindo e avaliando.

Em Chronica Mobilis, a pesquisadora-artista tomou uma rota empírica para o entendimento do fenômeno em uma prática criativa reflexiva. O processo criativo não foi meramente incorporado no desenrolar da pesquisa, mas teve foco central e permitiu chegar a conclusões capazes de gerar esclarecimento e aprimoramento da própria prática relacionada à criação de uma performance intermedial no espaço urbano. Esta etapa do estudo facilitou, ainda, uma conexão entre a experiência da pesquisadora-artista e a experiência do público na obra, conhecimento que é de extrema relevância no campo da arte interativa, em que a participação é fundamental para a plena realização do trabalho. Os resultados não necessariamente se destinaram a maior aplicabilidade no sentido de confirmar ou desafiar teorias ou princípios existentes. O conhecimento gerado pelo estudo serviu para uma reflexão individual e consciente do fazer artístico, assim como para uma compreensão mais sistemática sobre a forma pela qual pessoas interagem com a obra de arte criada.

\section{Legitimação do conhecimento}

Os conceitos de objetividade, validade e generalização quase sempre aparecem em discussões sobre a credibilidade da "pesquisa baseada em artes", sobretudo porque noções forjadas pela tradição empiricista considera que as interações entre pesquisador e participantes da pesquisa podem ser 
uma fonte potencial de distorção. O método baseado na prática artística, no entanto, não reivindica uma garantia epistemológica que esteja ancorada na crença de que a observação objetiva e a perspectiva externa é mais imparcial e confiável. Eisner (2006) avalia como a epistemologia tradicional emprega uma linguagem que tende a objetivar a natureza e que subestima que qualquer forma de conhecimento é uma construção e não simplesmente uma descoberta. Pesquisa, para ele, é um processo direcionado a ampliar a experiência humana e a promover compreensão.

Diferentes paradigmas podem abordar problemas de pesquisa usando métodos específicos e distintos. Ressaltando a existência de formas diversas de conhecer o mundo, Rolling (2013) adverte que isso não significa que um método científico seja mais confiável do que outro. O domínio quantitativo e estatístico, por exemplo, emprega regras de dedução e generalização para explicar a ordem natural das coisas. Usa, para isso, métodos de observação objetiva que são verificáveis, estáveis e replicáveis. Por outro lado, a "pesquisa baseada em arte" aborda questões que não podem ser medidas com exatidão, ou generalizadas como universalmente aplicáveis ou significativas em todos os contextos, partindo, por isso, para a criação de conhecimento em um sentido experiencial, construído por diferentes observadores a representar realidades variáveis e contingentes (Ibid.).

O domínio das Artes costuma privilegiar o hibridismo entre teorias empíricas, interpretativas e naturalistas como práticas de criação. A discussão sobre as condições da legitimação desse conhecimento gerado por metodologias de pesquisa que aproximam conhecimento científico e fazer artístico deve acontecer levando-se em consideração o que as garantias epistemológicas significam hoje em dia. Lather (1993), por exemplo, tenta reinscrever a ideia de validade partindo de uma abordagem pós-positivista e de um contexto atual caracterizado pela perda de certezas e marcos de referência absolutos. Defende uma rearticulação do conceito que considera as críticas pós-epistêmicas ao realismo, ao universalismo e ao individualismo com uma validade descentralizada tomando o lugar daquela que mascara a natureza retórica das reivindicações científicas, usando para isso garantias metodológicas (Ibid., p. 676). Aponta para uma redefinição de validade que é múltipla, parcial, infinitamente diferida cuja legitimação depende da capacidade do pesquisador em 
explorar as fontes sobre as diferentes problemáticas contemporâneas. A validade, nesse caso, significa mais uma incitação a ver e um aparelho para observar e ser visto "o impensado em nosso pensamento" (Ibid.).

Galloway (2008) também argumenta sobre uma espécie de validação interpretativa contemporânea que se baseia em um entendimento teórico de que o que os pesquisadores testemunham, participam e criam é sempre múltiplo e parcial. Explora as complexas relações entre ver, fazer e escrever como algo capaz de gerar um conhecimento mais produtivo, que é mais processual e relacional do que estrutural, que conta muitas histórias subjetivamente em vez de objetivamente, que levanta mais questões do que fornece respostas (Ibid., p. 36). Interpreta essa abordagem metodológica como mais produtiva exatamente porque deixa o assunto aberto e fornece aos leitores múltiplas entradas passivas de interpretação.

\section{Conclusão}

Este artigo discutiu como conhecimento também pode ser ganho com o processo prático de criação artística sendo incluído como um método na pesquisa acadêmica. Analisou de que forma a prática, tida enquanto modo essencial de investigação, representa não apenas dados para o estudo, mas desempenha papel importante na análise do fenômeno pesquisado. Detalhou o processo de investigação e de criação da performance Chronica Mobilis, em uma tentativa de documentar uma bricolagem metodológica entre métodos científicos tradicionais e prática e experiência artística. Descreveu as atividades realizadas pelo pesquisador-praticante, que envolveu prática, teoria e avaliação, compreendidos no processo de criação da performance, no desenvolvimento de estruturas conceituais e na realização de estudos de avaliação da experiência com a obra. Essa metodologia, especialmente aplicada para explorar a natureza da experiência artística e de sua criação, oferece ferramentas alternativas de pesquisa ao também considerar o processo epistemológico do saber-fazer. Este artigo detalhou uma abordagem metodológica passível de ser replicada e implementada por outros pesquisadores, no intuito de auxiliar futuras aplicações em estudos acadêmicos no âmbito das Artes e das Ciências Humanas. 


\section{Referências bibliográficas}

ACETI, L. Meanderings and reflections on locative art. Leonardo Electronic Almanac, San Francisco, v. 21, n. 1, p. 10-13, 2016.

CANDY, L. Research and creative practice. In: CANDY, L; EDMONDS, E. A. (org.). Interacting: art, research and the creative practitioner. Faringdon: Libri Publishing Ltd, 2011. p. 33-59.

DEBORD, G. Theory of the Dérive. Internationale Situationniste, Paris, v. 2, p. 50-54, 1958.

EISNER, E. Does arts-based research have a future? Inaugural lecture for the first European conference on arts-based research Belfast, Northern Ireland, June 2005. Studies in Art Education, Abingdon, v. 48, n. 1, p. 9-18, 2006.

GALLOWAY, A. A brief history of the future of urban computing and locative media. 2008. 304 f. Tese (Doutorado em Filosofia) - Departmento de Sociologia e Antropologia, Carleton University, Ottawa, 2008.

GREENWOOD, J. The limits of language: a case study of an arts-based research exploration. New Zealand Journal of Research in Performing Arts and Education: Nga mahi a Rehia no Aotearoa, Christchurch, v. 6, p. 89-100, 2016.

KINCHELOE, J. L. On to the next level: continuing the conceptualization of the bricolage. Qualitative Inquiry, Thousand Oaks, v. 11, n. 3, p. 323-350, 2005.

LATHER, P. Fertile obsession: validity after poststructuralism. The Sociological Quarterly, Abingdon, v. 34, n. 4, p. 673-693, 1993.

LEMOS, A.; JOSGRILBERG, F. Comunicação e mobilidade: aspectos socioculturais das tecnologias móveis de comunicação no Brasil. Salvador: Edufba, 2009. MCNIFF, S. Art-based research. In: KNOWLES, J. G.; COLE, A. L. (org.). Handbook of the arts in qualitative research: perspectives, methodologies, examples, and issues. Thousand Oaks: Sage Publications, 2008. p. 29-40.

ROLLING, J. H. Arts-based research primer. Nova lorque: Peter Lang, 2013.

SHELLER, M; IVERSON, H. L.A. Re.Play: Mobile Network Culture in Placemaking, Leonardo Electronic Almanac, San Francisco, v. 21, n. 1, p. 14-25, 2016.

TUTERS, M.; VARNELIS, K. Beyond locative media: giving shape to the internet of things. Leonardo Electronic Almanac, San Francisco, v. 39, n. 4, p. 357-363, 2006.

ZIMMERMAN, E. Play as research: the iterative design process. In: LAUREL, B. Design research: methods and perspectives. Cambridge, MA: MIT Press, 2003. p. 176-184.

Recebido em 14/08/2017

Aprovado em 24/11/2017

Publicado em 03/05/2018 